\title{
A systems engineering study of integration reverse vending machines into the waste management system of Kazakhstan
}

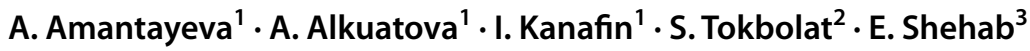

Received: 25 June 2020 / Accepted: 7 December 2020 / Published online: 23 February 2021

(c) The Author(s) 2021

\begin{abstract}
This study aimed to conduct a systems engineering investigation for the integration of reverse vending machines (RVM) into the waste management system of Kazakhstan. By conducting a wide-scale survey among the general public, the study was able to identify the underlining reasons for low recycling rate, the awareness and willingness of the public to engage with RVMs, and incentives that would motivate them. Survey results also allowed identifying the customer (user) requirements and helped to design the house of quality (HoQ) for further evaluation of potential RVM functionality. The proposed system model and functional flow block diagram (FFBD) were developed for an RVM considering identified customer requirements. Finally, risk analysis of RVM integration to the waste management system was carried out, and mitigation measures were proposed.
\end{abstract}

Keywords Reverse vending machine $\cdot$ Functional flow block diagram $\cdot$ Survey $\cdot$ Recycling $\cdot$ Kazakhstan $\cdot$ House of quality

\section{Introduction}

Effective waste collection and segregation is a critical element of a waste management system of any country and a strategic solution for ensuring environmental sustainability. In developing countries with growing economies and increasing consumption of goods, the waste generation increases continuously. In Kazakhstan, particular challenges are evident concerning plastic collection and recycling. At present, despite the measures introduced by the government to encourage the general public to segregate waste and recycle as well as the willingness of individuals to do so, there is still no clear strategy on how to motivate people to segregate and recycle plastic items.

E. Shehab

essam.shehab@nu.edu.kz

1 Dept of Civil and Environmental Engineering, School of Engineering and Digital Sciences, Nazarbayev University, 53 Kabanbay Batyr Ave, Nur-Sultan 010000, Kazakhstan

2 Dept of Construction Management, School of Architecture, Design and the Built Environment, Nottingham Trent University, 50 Shakespeare street, Nottingham NG1 4FQ, UK

3 Dept of Mechanical and Aerospace Engineering, School of Engineering and Digital Sciences, Nazarbayev University, 53 Kabanbay Batyr Ave, Nur-Sultan 010000, Kazakhstan
The wide-scale application of plastic bottles started in the late 1970s when the first polyethylene terephthalate (PET) bottle was invented. It was far more lightweight, safer and cheaper than previously used materials such as glass and metal. This invention triggered increased beverage production leading to enormous plastic waste generation, which continues up today. Euromonitor International's global packaging trends report indicates that by the year 2017, there were almost 1 million plastic beverage bottles sold every minute [1]. Unfortunately, the significant portion of the plastic waste, including bottles, end up either in the oceans or landfills. The latest studies suggest that by the year 2050, the amount of plastic waste in the ocean will overweight the marine inhabitants [2]. The detrimental consequence of such unsustainable waste disposal can have a severe impact on ordinary individuals through food chains. For example, it was found that an average European fish consumer receives 11,000 microplastics - plastic particles $(<1 \mathrm{~mm})$ per year [3].

In the framework of global waste reduction efforts, while some states attempt to decrease the consumption of plastic through governmental policies and restrictions, the others try to sanction the manufacturing, importing and application of plastic by introducing penalties and fines. However, since currently, it is not possible to completely remove plastic from bottle production due to the affordability of alternative materials, 
the viable solution to reduce plastic production is recycling. At present, there are two main ways of plastic recycling such as mechanical and chemical recycling [4]. One of the critical challenges the recycling centers face is associated with the separation of varying plastic types before melting or shredding as some materials should be not mixed. Another challenge is related to the unsuitable condition of plastic bottles delivered to the plants, thus requiring extra resources for processing and purification. These challenges could be solved by more robust efforts to ensure waste segregation and recycling of plastic bottles by both waste management organizations and ordinary individuals. According to [5], there are several reasons for the low recycling rate. Those reasons are more or less universal across countries and are mainly related to awareness and phycological aspects. For example, $30 \%$ of respondents relate low recycling rate to unavailability of time, $14 \%$ explained by the lack of knowledge, $13 \%$ do not have adequate space or trash bins, $11 \%$ find the recycling facilities inconvenient, and $8 \%$ do not feel it is important [5]. The study by [6] suggests that to increase the recycling rate, the general public needs to see the results of their actions. For example, advertising the end products made from recycled materials could be a very strong incentive.

One potential solution to appeal to awareness and phycological motivation could be reverse vending machines (RVMs). An example of an RVM is shown in Fig. 1. The first RVM was known as "Bottle return and Handling machine" and was created in the USA in 1920. Currently, there are more than 100,000 RVMs are installed all across the globe [7]. It is a type of vending machine that accepts empty plastic bottles and pays back to a user either by cash or a deposit receipt, which could be used in supermarkets and other places. The principle of RVM's work is quite simple. The user deposits a bottle which is automatically rotated for bar-code scanning. After the code is identified and matched with universal product code (UPC) in a database, the item is moved to a compressor and further to a container. Some RVMs use a material recognition system by weighting the item instead of scanning. According to the survey conducted by the New York City Housing Authority (NYCHA), participants felt that RVMs would be the most flexible option and that they can be located closer to their buildings than waste collection points; thus, it can be more convenient [8]. Moreover, RVMs are perceived to contribute to the circular economy, facilitating the general public participation in recycling schemes [8]. The monetary incentive that is provided by RVMs is strong motivation to engage the general public in recycling efforts. In some countries, governments introduce special regulations to implement a deposit-based recycling system. For example, Finland's government introduced a law that enforced the introduction of deposit-refund systems [9].

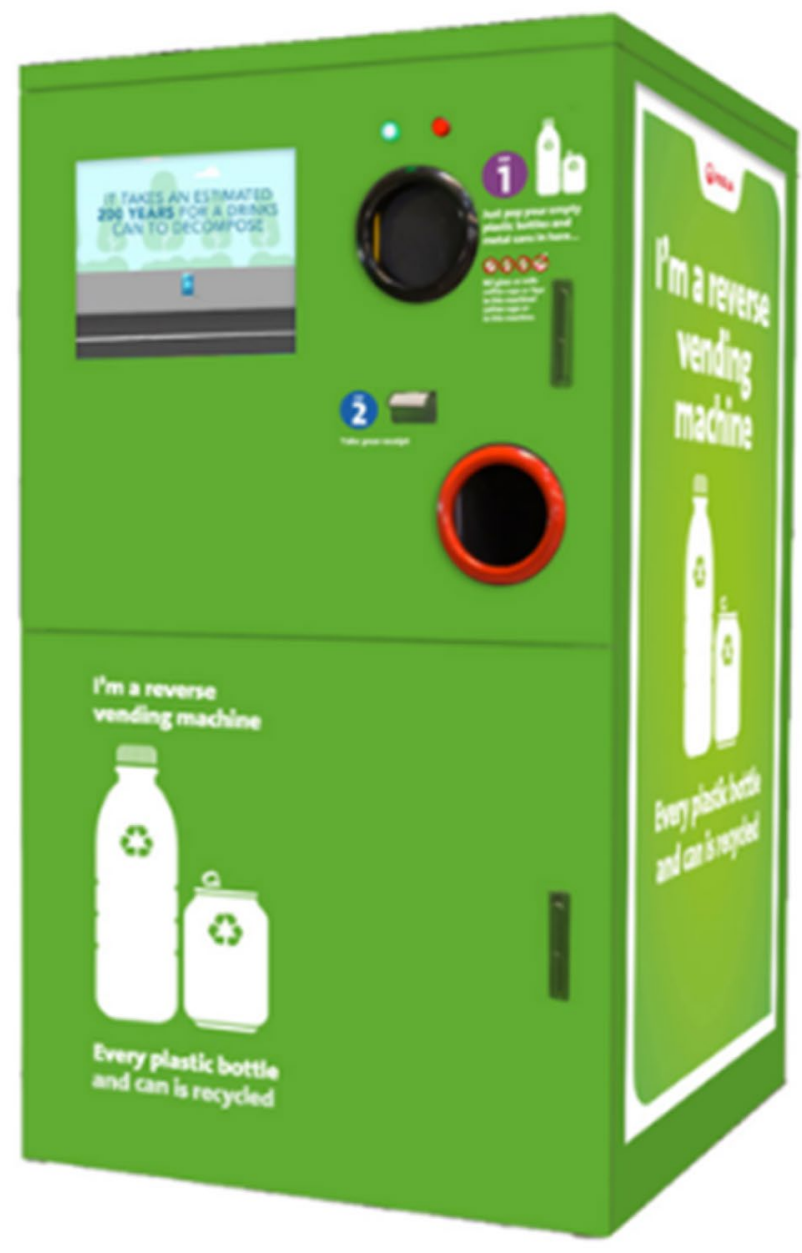

Fig. 1 A typical reverse vending machine (RVM) [10]

To successfully implement the RVM concept in Kazakhstan, several countries where RVMs are already implemented were considered. For example, Norway has become the worldwide leader in fighting plastic waste. According to [11], there are around 3700 reverse vending machines inside the country and more than 12000 reception points where citizens can return plastic for recycling. The success of Norway lies in its strong motivational incentive system, where the refund is paid back by giving the money by cash or deducting the final bill in the end.

Another country with a prosperous vision is Japan. The success behind their biggest RVM production company is mostly represented by bringing the outside investment from business partners by acknowledging that RVM improves the company brand image and promotes an eco-friendly environment. The bills that the customers get from the RVM can only be used in specific storage shops, which results in a bigger customer retention rate.

In India, the first RVM was set in 2016. The plastic waste was provided to fiber-manufacturing companies to make 
clothers or grocery bags. The benefits from using RVM were mostly described as being beneficial for the society by using charity and donations, rather than personal benefit [7].

Russia has also shown great steps in the implementation of RVM. In 2019, one of the Russian food retailers paired with one of the world's biggest beverage producers to put up tests of RVM in many shops. Their idea was to put a $15 \%$ discount coupon, which is applicable for the different variety of beverage producers' range of drinks. The joint pilot is still going through the tests, but so far according to food retailers, the idea looks promising as the first step to a "World Without Waste" movement [12]. Since it is a new concept for Russia, it can be a great example to use in Kazakhstan as well, mostly because the neighboring countries share several cultural similarities.

A feasibility study by [9] considered several case studies comparing RVM integration in Finland and Kenya. For example, in order to stimulate beverage producers to recycle, the government of Finland introduced a tax for every liter produced. As a result, producers joined to recycling communities in order to avoid taxes. Generally, it is reported that recycling practices in Finland are well established in people's mentality, thus eliminating the need for additional incentives. In case of Kenya, due to a lack of laws and regulations that deal with plastic, the actions are mainly limited to young people who voluntarily choose to collect and recycle. The authors state that although some supermarkets are able to integrate RVMs, they are not willing to invest. It was found that the predominant majority of supermarket managers are not aware of recycling solutions and, particularly, of reverse vending machines.

According to the literature review conducted by this study, there are various effective schemes such as, for example, return-to-retail legislation that encourages supermarkets to collect bottles from sold beverages. Germany is one of the countries that implemented this system and showed impressive results. For example, $98 \%$ of plastic and $99 \%$ of the aluminum were returned for recycling in 2003 [13]. On the other hand, regions without return-to-retail policy return only $48 \%$ to $77 \%$ [13].

The situation in Kazakhstan with waste processing and utilization is extremely poor and incomparable with European countries [14]. The recycling rate reaches only up to $5 \%$, and the vast majority of waste, including plastic, is just stored in outdoor dumps and consequently sent to landfills or incinerating plants [14]. At present, the separate waste collection bins are installed only in a few cities. Special programs were launched through public-private partnerships to popularize and implement recycling schemes. The awareness of the general public has been rising very slowly and mainly in big cities such as the new and old capitals of Kazakhstan, namely Nur-Sultan and Almaty [14]. Although various solutions exist and known to the government, their implementation requires not only moderate changes but rather complex legislative enforcements and enormous financial investments. The idea behind RVM in Kazakhstan is to gather and sort the plastic that is used the most (polyethylene, foam, caps, PET bottles, containers for household chemicals and cosmetics, clean blisters, any plastic food packaging) and metal packaging (aluminum cans and tin). Bottles made of polyethylene terephthalate (soft drinks, beverages, cosmetics) may be cleaned and reused as bottles once again, or be offered for sale further to create plastic bags in local companies alongside HDPE type of plastic since it is highly reusable [15]. Polystyrene plastic is not reusable; therefore, RVM will only gather and sort it, and later sell it at a low price to construction companies to use it in construction with the combination of plastic and construction material. There is a lack of research on the analysis of deposit-refund systems such as RVMs in Kazakhstan. This paper aims to narrow this research gap by conducting a feasibility study on the integration of RVMs into the waste management system of Kazakhstan.

\section{Methodology}

This study aimed to understand the feasibility of the integration of RVMs into the waste management system of Kazakhstan. This would require gauging the opinions of all stakeholders that would be engaged with the potential integration process. However, it was decided to limit the scope of the study by engaging only the general public, which would be one of the key stakeholders in the successful implementation of the system. By conducting a widescale survey among the general public, the study aimed to identify the underlining reasons for low recycling rate, the awareness and willingness of the public to engage with RVMs, and also to obtain more insights on incentives that would motivate them the most. Firstly, analyzing these parameters was helpful to understand the general public's opinion as well as the problems and potential customer requirements of the system. Secondly, based on the analysis of survey results, the house of quality (HoQ) was developed containing the necessary information, including customer requirements, functional requirements and competitor analysis for further evaluation of potential RVM functionality. The proposed system model and functional flow block diagram (FFBD) were developed for an RVM considering identified customer requirements to explain the operation of the system around the RVM and the internal process of RVM itself. Finally, risk analysis of RVM integration to the waste management system was carried out to propose mitigation and contingency measures. 


\section{Survey}

The customer requirements are identified by creating a marketing survey, which serves as a starting point and is targeted toward end users of the product, and is very efficient for solving new design problems [16]. The survey questionnaire was created in one of the commonly used platforms, Google Forms. The link to the questionnaire was distributed among the general public of Nur-Sultan city, the capital of Kazakhstan via e-mails and social network platforms. The questionnaire contained 11 general questions about the demographic background information and recycling habits of ordinary individuals, their incentive and location preferences as well as their opinion on RVMs. The total number of collected responses was 577. The minimum required sample size was calculated using parameters such as population size, confidence interval, error margin and standard deviation. The population size was considered to be the number of people living in Nur-Sultan city-1.18 million [14]. The confidence level was chosen to be $98 \%$ with corresponding $Z$ value 2.33. The sample size was calculated using Eq. 1 [17].

$S S=\frac{Z^{2} p(p-1)}{c^{2}}$

where $Z-Z$ value for confidence level (2.33), $p-$ probability of choice (50\%) and $c-$ margin of error $(5 \%)$ [17]. The correction formula for the sample size is shown in Eq. 2 [17].

Corrected $S S=\frac{S S \times P S}{P S+S S-1}$

where $S S$-sample size and $P S$-population size $(1.18$ million).

In this case, the sample size appeared to be equal to the corrected sample size, which is 542. This implies that at least 542 people need to reply in order to draw valid conclusions. Thus, the number of collected responses 572 was deemed to be satisfactory.

\section{House of quality (HoQ)}

Based on the survey results, the HoQ matrix was developed and the main customer requirements were identified. The HoQ is a commonly adopted process for product development based on customer requirements [18]. It is a part of the process named QFD (quality function deployment) which helps to execute quality plan applying resources for its deployment. It helps to understand customer desires and their priorities, transform customer desires into goals and specify traceble requirements [18]. This especially helpful during the define phase of the project. In other words, HoQ results become inputs for process planning design stage, which, in turn, become input for production planning phase [19]. According to [20], there are six main steps to build HoQ. The HoQ matrix columns contain information of functional requirements for the RVM system and the matrix rows contain customer requirements for the design of an RVM. The relationship between these requirements was identified and prioritized according to their weights. Current competitors were analyzed and ranked accordingly.

\section{System model}

In this section, the desired system model is developed. The system development is an important aspect in depicting the larger-scale picture, which consists of "interrelated and interdependent elements" (components, entities, factors, members, parts, etc.). These system elements interchangeably influence each other to adhere to their purpose and keep the system working to meet the system's objective [21]. The system developed in this study was an important step to describe components that are needed for an RVM to work effectively. Since an RVM is a not just a self-contained box, but rather a smart machine which requires interaction with users, waste collectors, IT support and technical maintenance teams as well as the vendors which provide space for locating the machine, the developed system should clearly describe all the components and their relationships.

\section{Functional flow block diagram (FFBD)}

The sequential relationship between the functions of the internal system of an RVM that is developed based on the survey results as well as the HoQ can be depicted by FFBD. A functional flow block diagram is a multi-level, subsequent, step-bystep stream diagram of a system's functional flow [22]. In this case, the diagram shows two levels of second-level operations. Second level A refers to the process plastic function, which is initiated by the move of the plastic through the pipes. Second level B shows the sequence of the incentive transfer operation. This diagram is developed to help the respective stakeholders who will potentially develop their own RVM rather than simply purchasing a manufactured one.

\section{Risk analysis}

While development and operation stages of an RVM and RVM-related system model, several risks may occur that may negatively affect the operation of the machine or the system. In order to prevent or mitigate the possible risks, the analysis of the risk needs to be carried out. A simple risk analysis approach for RVM integration to the waste management system was performed, potentials risks were identified, and mitigation and contingency measures were proposed. 


\section{Results and discussion}

\section{Survey}

This section summarizes the analyzed data obtained from the survey. Figure 2 describes the demography of the respondents' pool. There is a gender disproportion between the males (32\%) and females $(68 \%)$ who participated in the survey. It is likely to be related to the fact that there is a tendency in Kazakhstan for females to be responsible for the household due to the traditional background of society. This is a probable reason to explain why more female respondents reacted to the survey rather than men since it is more related to females' everyday concerns. Such disproportionate gender representation took place despite the fact the questionnaire was distributed widely equally to both gender groups.

The majority of the respondents were young people aged 18-24 (32\%) and 25-35 (38\%) followed by adults aged $36-50(20 \%)$ and "50 and older" (8\%) and "18 or less" (2\%) categories, respectively. The predominance of young respondents and young adults can be linked to the fact these age groups are more engaged with social media and Internet platforms and also aware of recycling philosophy. There were fewer adults participated, but having their responses is very helpful in understanding the larger-scale picture of the society's perspective on recycling and RVMs in particular.

With regard to occupation of the survey respondents, the great majority indicated to be employed (61\%), followed by students $(27 \%)$ and unemployed individuals (12\%), the remaining $5 \%$ is represented by pupils (3\%) and retired people $(2 \%)$. The fact that the majority of respondents are employed or occupied by studying is a good opportunity to understand how the most active part of the population perceive the subject matter and engage in it. These two categories are of significant importance as they are the drivers of the economy and education system, and their awareness and choices may significantly affect the sustainability agenda of the country. Finally, the respondents' pool was asked to indicate the highest level of education they had or in the process of acquiring. According to the results, the great majority reported "to have or will have" Bachelor (64\%), Master (20\%) and Ph.D. (2\%) degrees, followed by respondents with high school-level education (14\%). This breakdown is useful to understand the correlation between the level of education
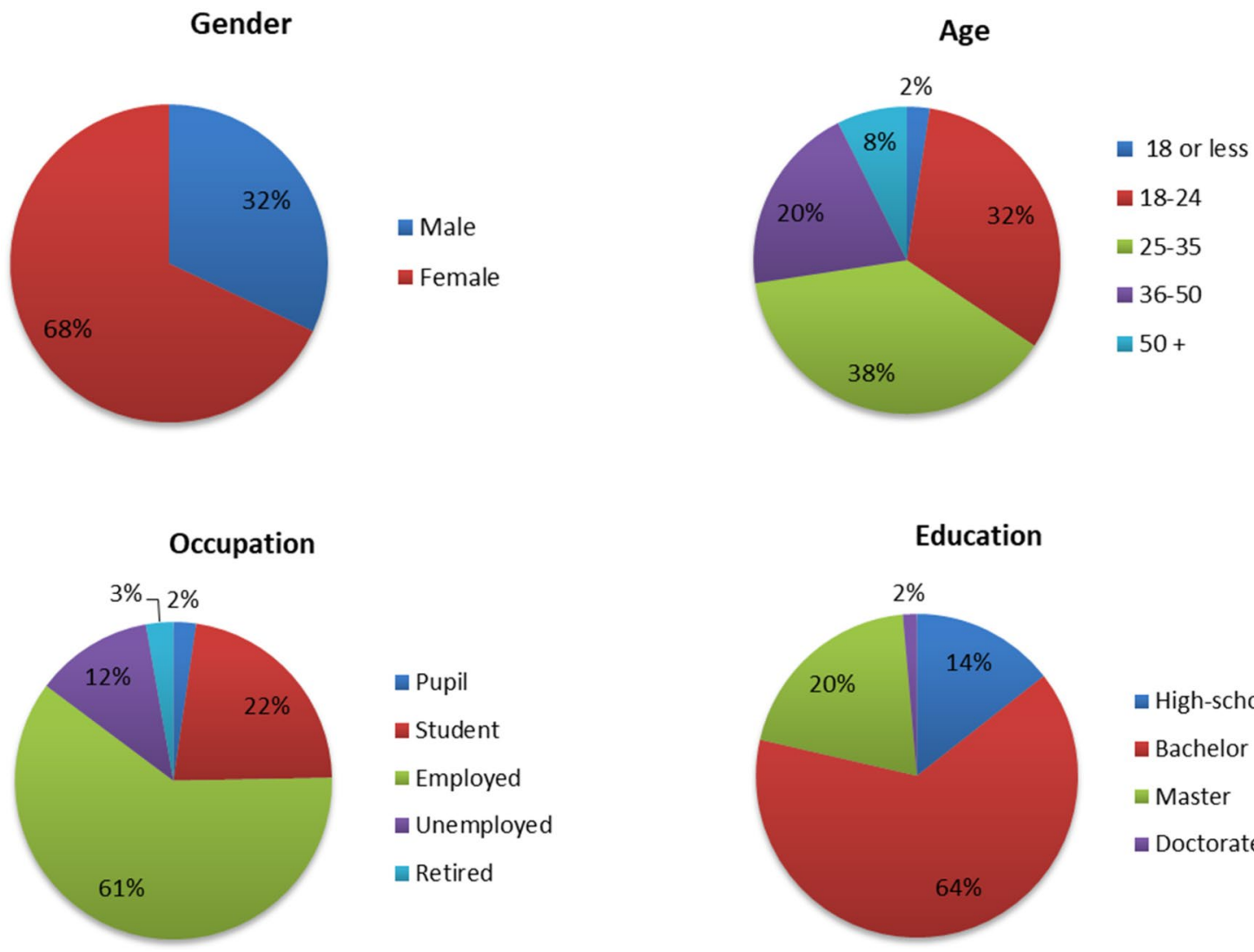

\section{Education}

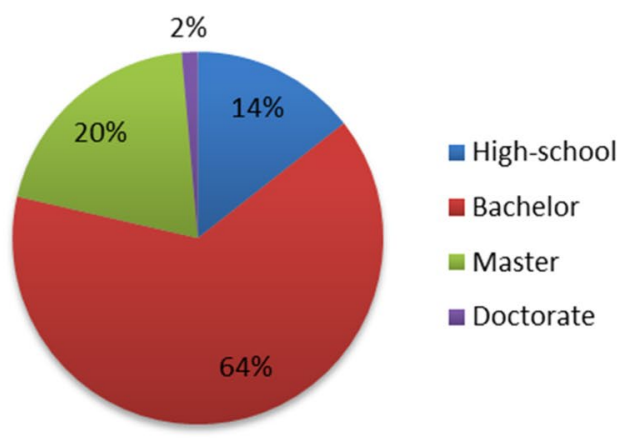

Fig. 2 Demographics of survey respondents 


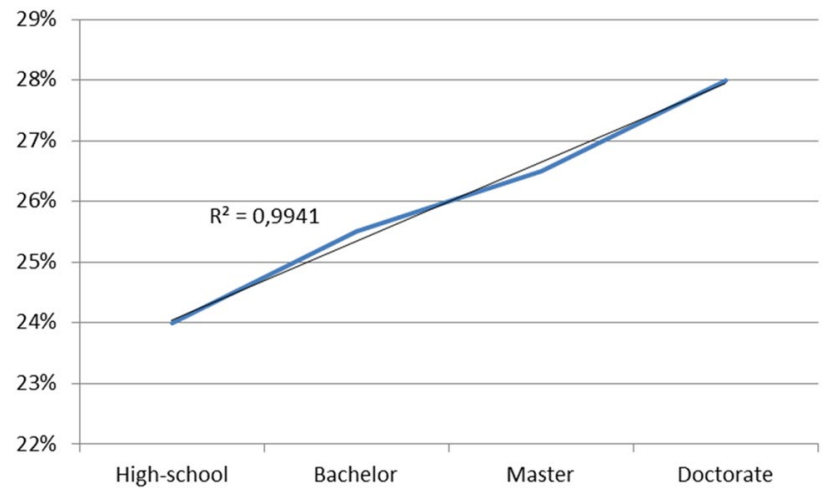

Fig. 3 Education level versus recycling rate

and the awareness of waste recycling as education is crucial for awareness raising and motivation. Figure 3 shows the strong positive correlation between education level and the percentage of people that recycle. The R2 value of 0.9941 means that approximately 98 percent of the variation in recycling rate data is due to variation in the education level data. Therefore, the higher the education level, the more the chance that people will recycle.

The next questions of the questionnaire reveal that the recycling rate is almost $26 \%$, which is quite reasonable, although the overall recycling culture is very poor in Kazakhstan. The high percentage can be explained considering the fact that the survey was conducted mainly among Nur-Sultan's population. As previously mentioned, big cities such as Nur-Sultan and Almaty have a few programs introduced by the government in place which allow people to separate their waste and submit for recycling. If a widerscale survey among the entire country's population is run, it would most likely show a much lesser percentage of people who recycle.

Further, respondents were asked regarding the reasons which hinder their engagement in recycling. Among the reasons that discourage people from recycling, 58\% of respondents answered that "recycling is not available in their region and/or is not convenient," $16 \%$ are "unaware about the recycling," $13 \%$ indicated that they "forget to recycle," $10 \%$ said that "it is time-consuming," and about $2 \%$ answered that they "don't care." $26 \%$ of respondents provided additional reasons for their initial selection. The results imply that recycling might be of interest to the general public; however, they do not have the right infrastructure and knowledge $(74 \%)$ as well as motivation and incentives $(23 \%)$. The RVMs could be a reasonable solution to address all of these challenges, given that all prerequisites are in place.

An additional argument for integrating RVMs can be found in the breakdown of the responses regarding the types of recyclable waste the respondents generate. It was found that the majority of domestic recyclable wastes are plastic

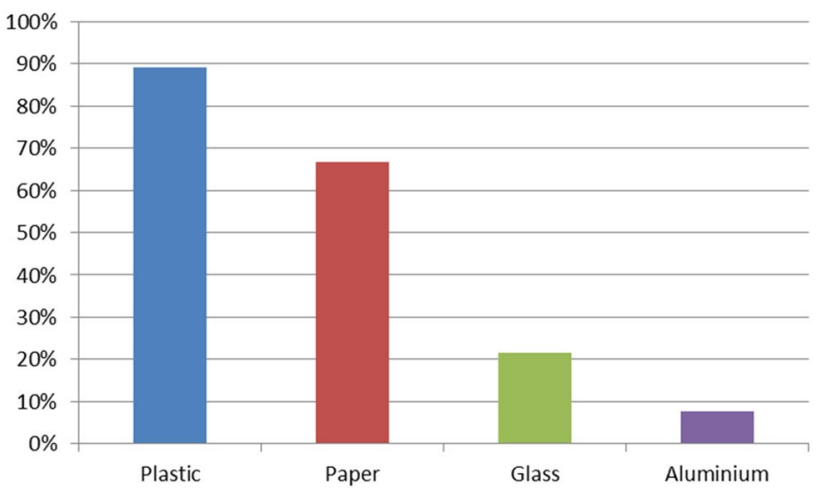

Fig. 4 Types of recyclable waste generated by respondents

(89.6\%), paper (66.8\%), glass (21.7\%) and aluminum (7.7\%), as shown in Fig. 4. Assuming that the high proportion of plastic waste tends to be plastic bottles, these survey results justify the need for RVMs to be integrated into the waste management system of Kazakhstan.

As for incentives that can be used for RVMs use, the highest ranking is "discounts and bonuses in supermarkets" (57.6\%), and others prefer "bank and bus card deposits" (38.8\% and $35.8 \%$, respectively), "donations" (38.8\%), followed by "Wi-Fi distribution" (9.4\%) (Fig. 5). The results suggest that there is a need for the establishment of partnerships between RVM owning parties with supermarkets and shopping malls that can accept the deposit/credit issued by the machines. These could bonuses or discounts offered by partners. For example, the deposit could be used during shopping, covering part of the cost of groceries and goods. Partnering with mobile operators and transportation companies can also be beneficial for both parties. The Wi-Fi distribution could also be a useful incentive for RVM users since there is no wide-scale Internet coverage in Kazakhstan, and people often spend much money on it.

Location is another important criterion for designing an RVM system because the strategic placement of an RVM

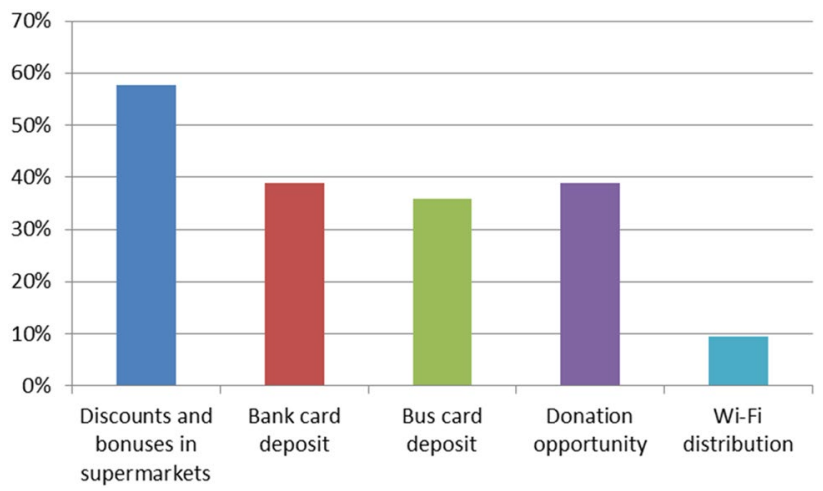

Fig. 5 Types of incentives motivating respondents to use RVMs 
will directly impact on the capacity of the machine and the number of users. The places suggested rated by respondents are tend to have a high volume of visitors. The highest ranking location for placing a RVM is "near neighborhoods" (56.6\%), supermarkets (49.2\%), bus stops (48.5\%), public places (47.8\%) and shopping malls (29.4\%). (Fig. 6).

In conclusion, respondents have high expectations from the implementation of potential RVM systems. As for the use of RVM, 96\% (536 people) answered that they would use it in case of successful implementation. In addition, about $90 \%$ of respondents state that RVM will make recycling accessible and straightforward. High support rates from survey respondents; thus, the general public indicates that the RVMs are feasible and should be used.

\section{House of quality (HoQ)}

On condition that the public education level will increase, and consequently, recycling becomes popular (Fig. 3), it is vital to make it as convenient and accessible as possible. Therefore, house of quality method was utilized to see further directions for the development. As there are more plastic waste generated in households (Fig. 4), functional requirements of RVM are designed to receive only plastic waste and differentiate it by plastic type using bar-code reader (columns 14-15). The left side of the HoQ (Fig. 7) is populated with the customer requirements that were identified from the survey. For example, Fig. 5 shows that discounts in supermarkets and donation opportunities are the most motivating incentives. Therefore, to achieve feasible rewards and social recognition (rows 3-4), RVM should increase the number of partners and be active in social network (columns 3-4). Finally, Fig. 6 shows that all the options are equally good potential locations to place RVM; therefore, short distance (row 1) has strong relationship with proximity to public locations (column 1). Other customer and functional requirements were found from additional suggestions of customers.

To the left of the "Customer Requirements" column demonstrates items that are the priority for a customer (an RVM

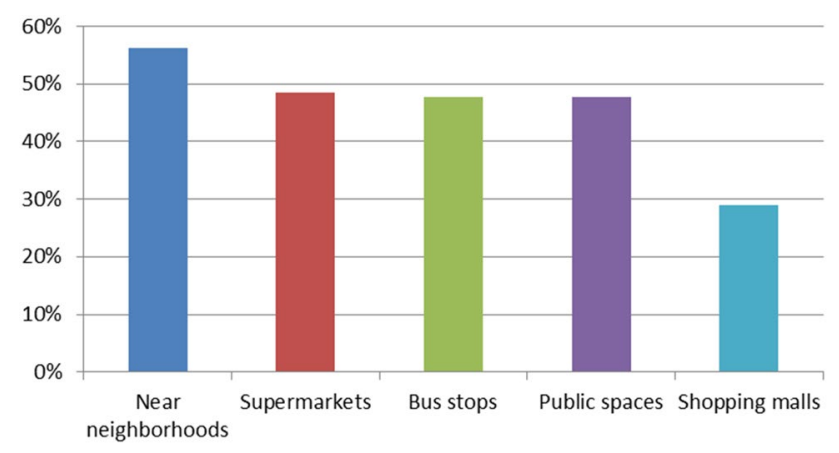

Fig. 6 RVM location preferences user) and calculates the relative weight of each requirement and their maximum relationship corresponding to functional requirements. As a result of customer specifications assessment, it can be concluded that the key customer requirements such as "easy to find," "feasible rewards," "easiness of usage" and "fast processing."

On the right side of the HoQ, these requirements are compared with the competitors in each category and assessed on a scale from 0 (none) to 5 (excellent). Then there is a trend line indicating the proposed RVM project and other ways of recycling used at present by the current market. During the assessment of current competitors, the data on separate bins and waste collection points were assumed based on common knowledge. This section concludes that the most of the customer needs are entirely in line with the current design of an RVM and show its superiority over current ways of recycling plastic in terms of several customer requirements, such as, for example, giving "feasible incentives" or being "odorless."

The top of the HoQ is a matrix that is looking at the synergy between design variables of functional requirements. Engineering requirements may have a positive correlation, negative correlation or no correlation at all. For example, there is a strong correlation between "appealing user interface" and "amount of useful information on the screen." The direction of improvement of each specification is identified in three directions: to maximize, to target or to minimize depending on the customer requirements. For example, in this case, the "size of a hole" should be targeted to be convenient for the customer, rather than just being big or small.

In the center of the HoQ is the relationship matrix. It is also called "rooms of the house." It shows the relationship between functional requirements and customer requirements. This is the most significant part of the HoQ, and it is created by intersecting the column of functional requirements with rows of customer requirements. First of all, the scale of relationships (strong, moderate and weak) was defined, and each scale was represented by a symbol [19]. This scale represents how strong the functional requirement is related or contributes to satisfying the corresponding row of the customer requirement. The numerical weights of relationships were represented by the exponential range of numbers (e.g., strong-9, moderate- 3 , weak-1), and empty cell represents no impact of functional requirement on the customer requirement [19]. For example, the number of partners such as stores, governmental organizations or individuals strongly affects the availability and easiness to find RVMs, moderately affect the proximity and the feasibility of rewards, and has no effect on other criteria.

After filling all the cells in, the technical importance rating was calculated by summing up the multiplication of the relative weight of customers' criteria and numerical values of relationships [20]. For instance, a customer wants 


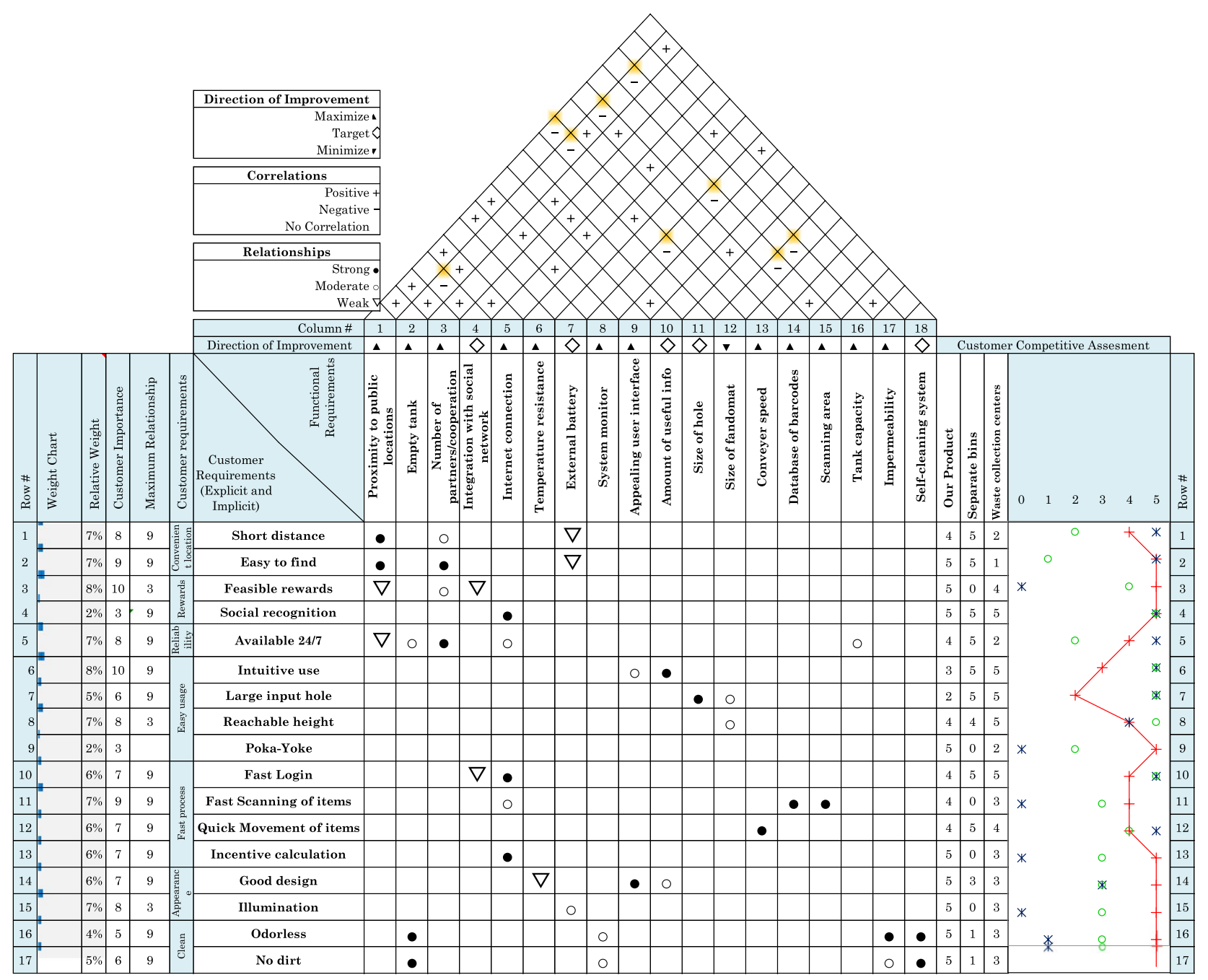

Fig. 7 House of quality matrix

to walk a short distance to reach RVMs. The customer's importance weight is $7 \%$. According to the first cell, it has a strong relationship (bold black circle) with proximity to public places, which has an importance rating of 9. So, multiplying 7 by 9 and repeating this with other rows and summing them up (e.g., $7 \times 9+7 \times 9+8 \times 1+7 \times 1)$ leads to the result 141 which shows the overall importance of being close to public places (written at the bottom of the table). The relative percentage weight was calculated by dividing the technical importance of each functional requirement to the total importance. These numbers allow seeing which parameters are essential and require to focus on so that customer requirements are fulfilled and reveal the relative importance of each parameter in the design process. The purpose of promoted survey was to identify find out what the consumers want from the consumers [16].
The foundation of the HoQ matrix also contains the target row, which is used to rank the functional requirements. The targets were chosen following customers' design criteria and engineering capabilities that satisfy them. For example, it is desirable to put one RVM in a radius of $3 \mathrm{~km}$ and empty tanks twice a day. Other parameters were also written in the form of a numerical target to assess the performance further.

The technical competitive assessment was completed at the bottom of the matrix. It represents how difficult it is to implement or reach targets of each functional requirement. It is a rough estimate of how well the design and project team can implement the desired values of customer requirements. Here, 1 means that there is a low chance to succeed, and 5 means there is a high chance. Competitors were also evaluated in this step. 


\begin{tabular}{|c|c|c|c|c|c|c|c|c|c|c|c|c|c|c|c|c|c|c|}
\hline Column \# & 1 & 2 & 3 & 4 & 5 & 6 & 7 & 8 & 9 & 10 & 11 & 12 & 13 & 14 & 15 & 16 & 17 & 18 \\
\hline Direction of Improvement & $\Delta$ & $\Delta$ & $\Delta$ & $\diamond$ & $\Delta$ & $\Delta$ & 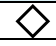 & $\Delta$ & $\Delta$ & $\vartheta$ & $\nabla$ & $\nabla$ & $\Delta$ & $\Delta$ & $\Delta$ & $\Delta$ & $\Delta$ & 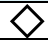 \\
\hline $\begin{array}{l}\text { Customer } \\
\text { Requirements } \\
\text { (Explicit and } \\
\text { Implicit) }\end{array}$ & 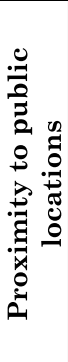 & 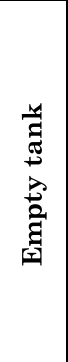 & 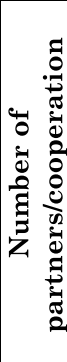 & 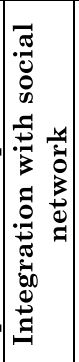 & 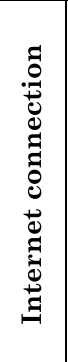 & 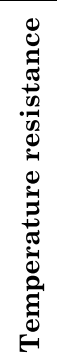 & 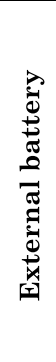 & 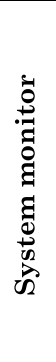 & 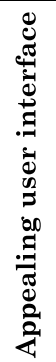 & 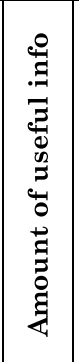 & 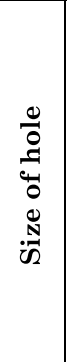 & 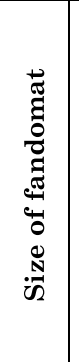 & $\begin{array}{l}0 \\
0 \\
0 \\
0 \\
0 \\
0 \\
0 \\
0 \\
0 \\
0 \\
0 \\
0\end{array}$ & 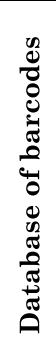 & 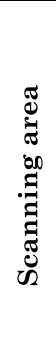 & 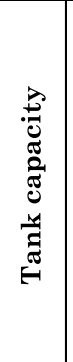 & 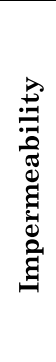 & 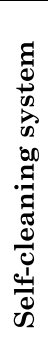 \\
\hline Target & 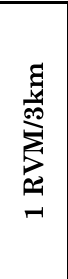 & 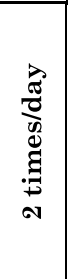 & $\stackrel{\circ}{\Lambda}$ & $\infty$ & 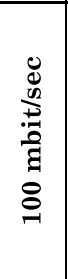 & 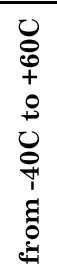 & 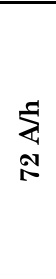 & 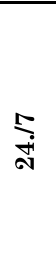 & 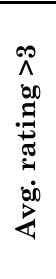 & 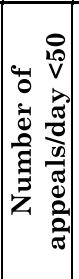 & 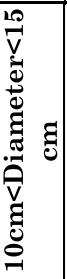 & 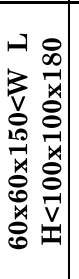 & 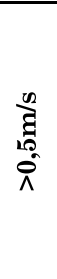 & $\begin{array}{l}0 \\
0 \\
0 \\
\vdots \\
0 \\
0 \\
\Lambda \\
\Lambda\end{array}$ & $\begin{array}{l}0 \\
0 \\
0 \\
0.0 \\
0 \\
0 \\
0 \\
8 \\
0 \\
0\end{array}$ & 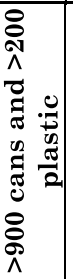 & 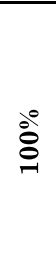 & $\frac{\vec{\sigma}}{\frac{\pi}{N}}$ \\
\hline Max Relationship & 9 & 9 & 9 & 1 & 9 & 1 & 3 & 3 & 9 & 9 & 9 & 3 & 9 & 9 & 9 & 3 & 9 & 9 \\
\hline Technical Importance Rating & 141 & 102 & 171 & 14 & 169 & 5.8 & 34 & 27 & 77 & 92 & 45 & 35 & 52 & 67 & 67 & 20 & 52 & 82 \\
\hline Relative Weight & $11 \%$ & $8 \%$ & $14 \%$ & $1 \%$ & $13 \%$ & $0 \%$ & $3 \%$ & $2 \%$ & $6 \%$ & $7 \%$ & $4 \%$ & $3 \%$ & $4 \%$ & $5 \%$ & $5 \%$ & $2 \%$ & $4 \%$ & $7 \%$ \\
\hline Weight Chart & 를 & 르 & 镸 & & 镸 & & - & - & $\equiv$ & $\equiv$ & - & - & $=$ & $=$ & $=$ & & $=$ & $\equiv$ \\
\hline Our Product & 5 & 5 & 5 & 5 & 4 & 3 & 4 & 3 & 4 & 2 & 4 & 3 & 3 & 3 & 3 & 3 & 5 & 5 \\
\hline Separate bins & 5 & 3 & 0 & 0 & 0 & 5 & 0 & 5 & 2 & 5 & 5 & 2 & 5 & 0 & 0 & 3 & 1 & 0 \\
\hline Waste collection centers & 1 & 5 & 4 & 4 & 0 & 5 & 0 & 3 & 3 & 3 & 5 & 5 & 2 & 2 & 2 & 5 & 4 & 5 \\
\hline 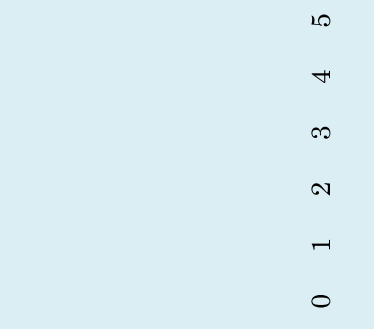 & * & * & * & * & * & * & * & * & $\begin{array}{c}\frac{x}{+} \\
*\end{array}$ & $\begin{array}{l}\text { Our Pro } \\
\text { Separat } \\
\text { Waste c }\end{array}$ & $\begin{array}{l}\text { duct } \\
\text { e bins } \\
\text { collectio }\end{array}$ & on cente & * & * & * & & & \\
\hline Column \# & 1 & 2 & 3 & 4 & 5 & 6 & 7 & 8 & 9 & 10 & 11 & 12 & 13 & 14 & 15 & 16 & 17 & 18 \\
\hline
\end{tabular}

Fig. 7 (continued)

\section{System model}

The proposed RVM system model (Fig. 8) was developed after the research on currently operating solutions worldwide. According to [23], the RVM industry as of 2017 was mainly consolidated with top few companies that takes the major share of the market such as Wincor Nixdorf, Holdings N.V., Repant ASA, Tomra Systems ASA, Envipco Holdings N.V., Aco Recycling, N\&W Global Vending Group and Spengler GMBH \& Co KG. Meanwhile, different countries nowadays are participating in designing and manufacturing their own solutions adding more features. For example newly added RVMs necessarily include mobile apps, multiple refund options, access to statistical data, cloud technologies, etc. (likewise Envirobank, recyclever ${ }^{\circledR}$ ).

In order to show the whole system consisting of several technical components essential to address customer requirements identified by the survey and depicted in a HoQ matrix, the use case diagram was developed. Use case diagrams typically made at early product development stages and perfectly demonstrate the actors/components involved in the system and their relationships [24]. [25] In their paper on reverse poverty proposed such diagram of the RVM system which includes the Microsoft Azure platform. They also presented activity diagrams and classes which can be highly beneficial in this study [25]. 


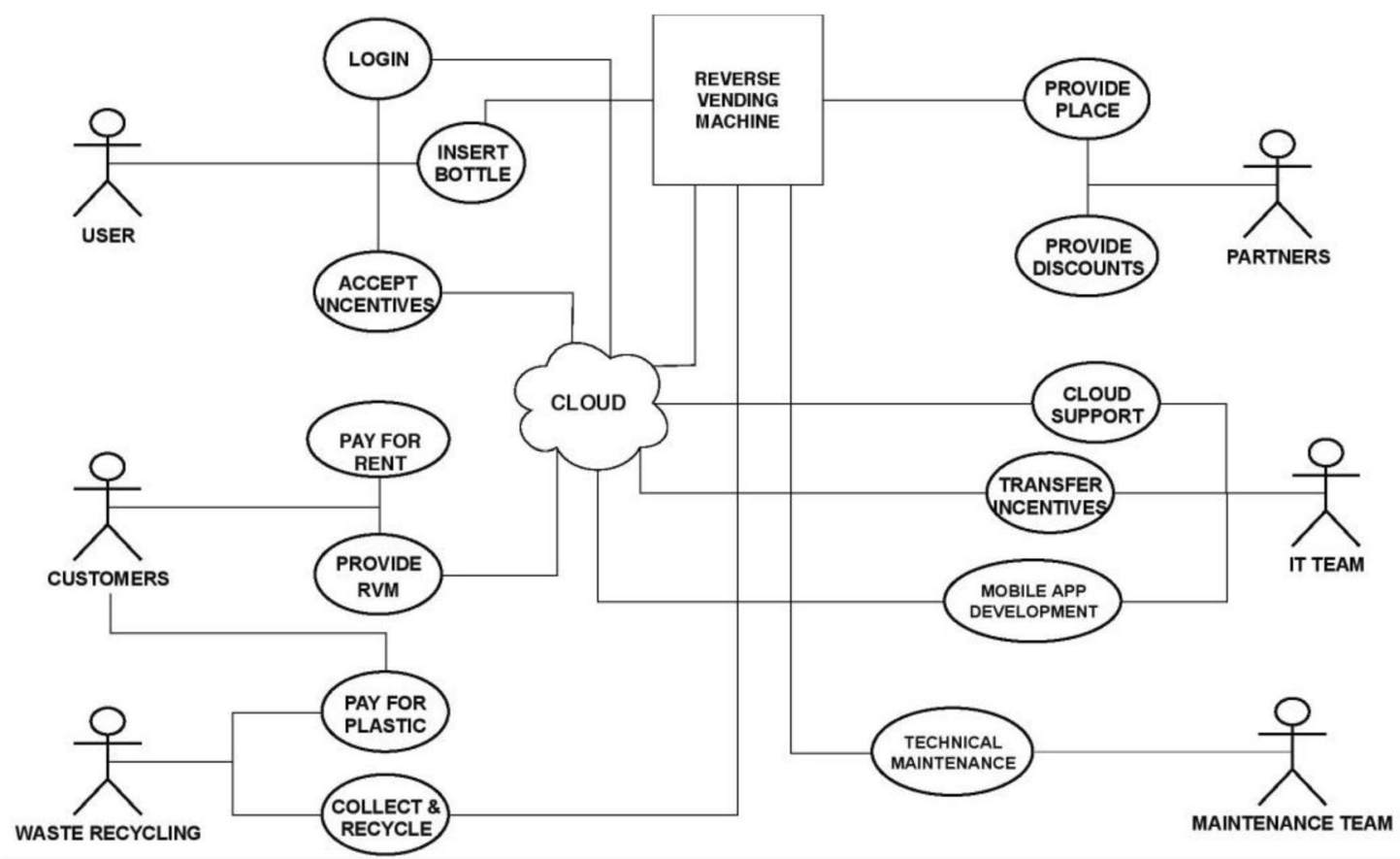

Fig. 8 Proposed system model

In the center of the proposing model is a cloud that stores the data and maintains the constant flow of information from an RVM to users, clients and administrating team, which is typically represented by an IT team. The RVM is equipped with temperature and weighting sensors and web cameras that are connected to the cloud via a wireless network for remote controlling and monitoring the system. The IT team is also responsible for the development and support of a mobile app that connects the end users with the system allowing the transfer of incentives, search for nearest RVMs. Besides the IT team, user and customer, there might also be business holders (partners) who buy and own RVMs. Partners are represented by supermarkets, bus stations, which can provide facilities, cleaning and security services. The waste recycling center is another partner that communicates with the owner of the RVM and regularly collects waste. The maintenance team is a separate actor that delivers technical services when the owner requires it.

\section{Functional flow block diagram (FFBD)}

FFBD is a useful tool for describing complex systems, and it was developed in 1950 by TWR Corp. as it was used to understand the behaviors of ballistic missiles. Knowledge and understanding of interactions within the system are crucial to develop a fully correctly operating machine [26]. The diagram in Fig. 9 is developed to provide a step-bystep sequence of operational procedures that run inside an RVM. The diagram is useful for stakeholders as customers, or RVM developers can be aware of the main procedures in general as well as in each component of the system.

The model is depicted in a way that it starts the analysis at top level through the systems level and goes down to the subsystem level by further describing the function model [27]. The proposed FFBD also shows general case as in top level function with its subfunctions in detail. The top level represents the main procedures that consist of seven steps, two of which are described in detail as they contain far more steps beyond. The plastic processing (second level A) starts when an item is inserted (a plastic bottle, in this case); further, it is moved through the channel to the scanning area. There it is pushed further to a bin or is returned back to the user in case of incompatibility due to dirt or contained liquid. The scanning of bottle itself is a major and essential process. According to [28], the inserting plastic is checked by 3 sensors:

1. Capacitive proximity sensor.

2. Infrared photoelectric sensor.

3. Strain gauge weight sensor.

The accepted item triggers further the "transfer of incentives" process, which is also shown in detail on the second level B. The signal of the bottle acceptance is communicated to the server for validation in accordance with the selected option of the user. Incentives such as donations, discounts and bus pass deposits can be selected. The final step is the issuing/enrollment of incentives to a user/account. 


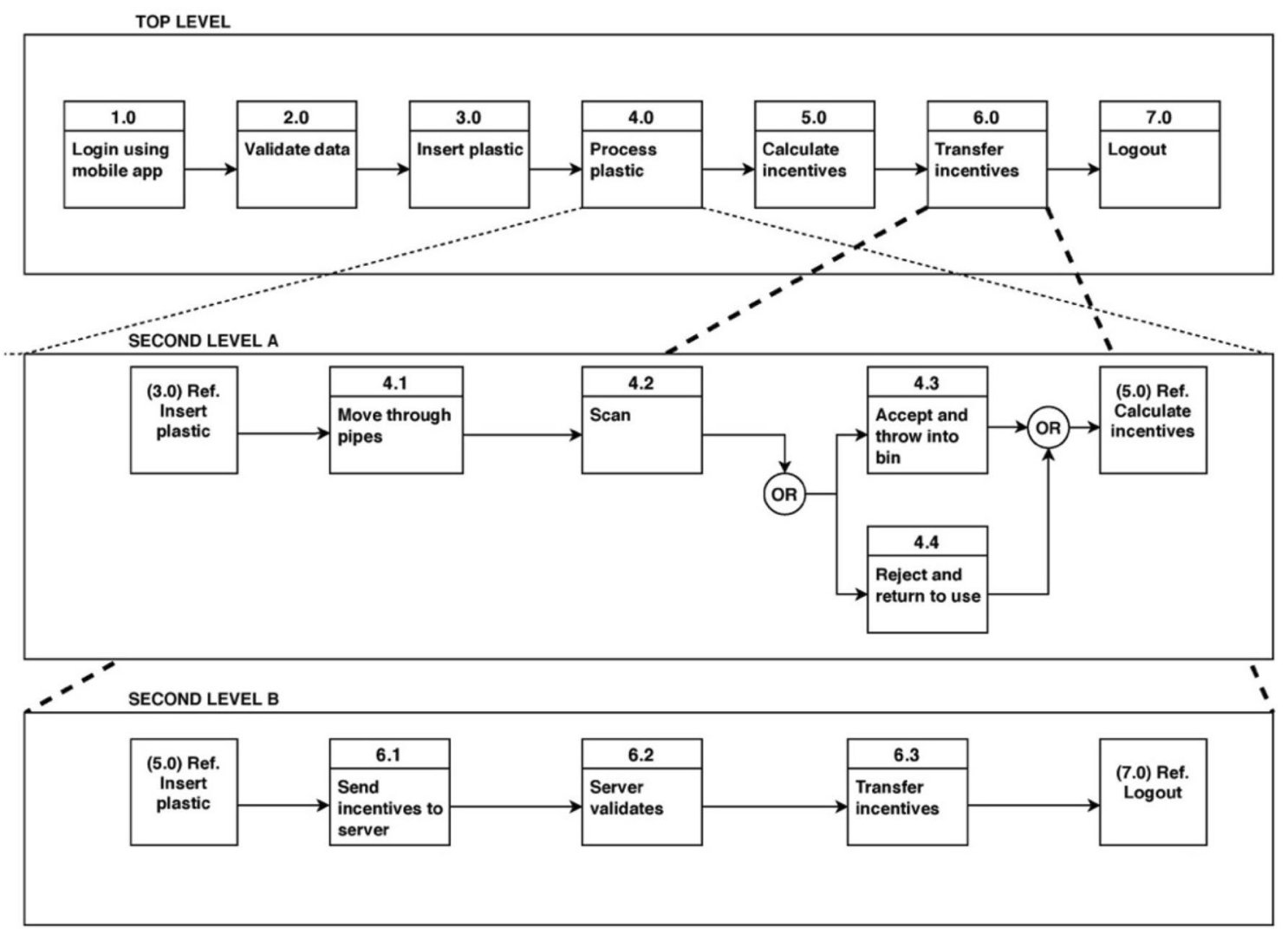

Fig. 9 Functional flow block diagram

From the above analysis, FFBD has shown the whole system for RVM functions and user needs. It provides the clear vision of subfunctions, meaning that it helps designers to answer which function from top to lower level will change or how it will affect other level functions [29].

\section{Risk analysis}

The summary of risk analysis for an RVM's successful operation, as well as the business plan of RVM system implementation, is shown in Tables 1, 2 .
Besides the above-mentioned common risks, there are some issues that should be discussed: for example, the Jevons Paradox, which states that the more the plastic cans and bottles are recycled, the more the people are likely to consume such goods rather than decrease the usage. Nevertheless, this is a common issue for any project and RVM overall tend to decrease the consumption and production of plastic or other types of bottles. The other issue is the size and model of the machine. For example, Envirobank provides machines of different sizes and capacities and even the mobile cruncher model which might be very useful for temporarily events and festivals. It is important to design

Table 1 Risk analysis of RVM's successful operation

\begin{tabular}{|c|c|c|}
\hline Risk & Mitigation & Contingency measure \\
\hline $\begin{array}{l}\text { Users may feel reluctant to come back due to rejection of } \\
\text { plastic by an RVM }\end{array}$ & $\begin{array}{l}\text { Promotion of instructional videos and materials } \\
\text { (on the RVM) }\end{array}$ & Putting the trash bin nearby \\
\hline Suspicious views of conservative people & Wide reporting the results on a regular basis & $\begin{array}{l}\text { Activities to raise awareness } \\
\text { among the general public }\end{array}$ \\
\hline The unwillingness of people to go to an RVM & Strategic location and placement of RVMs & Increase the incentives \\
\hline The unwillingness of users to download the mobile app & Intense advertisement online & Bonuses for downloading \\
\hline Unreliability of the machine & Constant monitoring and improvement & Innovation and development \\
\hline
\end{tabular}


Table 2 Risk analysis of RVM business plan

\begin{tabular}{|c|c|c|}
\hline Risk & Mitigation & Contingency measure \\
\hline $\begin{array}{l}\text { Poor cleanliness near an RVM might deter } \\
\text { from potential partnering }\end{array}$ & The self-clean system inside the RVM & Regular emptying an RVM \\
\hline $\begin{array}{l}\text { A lack of finances for mass manufacturing of } \\
\text { the RVM }\end{array}$ & Participation in Start-Up programs & Attract finances from interested stakeholders \\
\hline Prototype-making may take too long & Outsource the work to professional engineers & Attract finances from interested stakeholders \\
\hline Competitors & $\begin{array}{l}\text { Use first-mover advantage to establish con- } \\
\text { nections }\end{array}$ & Develop marketing strategy/increase incentives \\
\hline No interest from partners' side & Present feasibility analysis & Apply for governmental support \\
\hline
\end{tabular}

an equipment which will be suitable for different areas and customers.

Social factor of the usage of machines is the most crucial aspect in the whole project as these machines are helpful only when people constantly and carefully use it; otherwise, they could easily malfunction. The only contingency measure here is to guide people through the mature user experience and user interface [30].

\section{Conclusion}

The feasibility study of integration RVMs in the waste management system in Kazakhstan was carried out using a survey and subsequent development of HoQ, RVM system model and FFBD. The survey results suggest that the general public is eager to use RVMs; however, some conditions have to be met. First, it is necessary to educate the general public using wide-scale advertising, mobile applications and informative billboards. Second, RVMs should be located according to customer requirements near residential complexes, supermarkets, etc. Third, both extrinsic (charity donations) and intrinsic (discounts, bonuses and balance card replenishment) incentives can be used to increase the general public's involvement. Compliance with the identified customer and functional requirements depicted by the HoQ matrix, the designed FFBD and RVM system model as well as the findings of the risk analysis can improve the current waste management system and the general cycle economy of the country. As a result, this will help to achieve the country's targets of minimizing waste and increasing awareness among the general public on the recycling problem and motivate to change their lifestyles and habits. The governmental agencies can use the results obtained from this study along with researchers, the business community and the society as a whole for further more in-depth analysis of reverse vending technologies.

Finally, prototype development for RVMs could help in the development of technical features and functionality for Kazakhstan's reality. If such experiments succeed in Nur-Sultan, surveying other cities of Kazakhstan has to be considered for generalizing the findings and tailored development for each locality's needs. Benchmarking and experience of other countries should be further investigated. As the prototype will be fully ready, the cost analysis for mass manufacturing should be conducted. The study has initially looked at the cost-benefit analysis which considered the initial cost of the RVM and payback period. However, it was envisaged that this calculation should be considered in the future research. The wide-scale survey is recommended to acquire enough data from supermarkets, manufacturers and general public to understand the long-term feasibility of the RVM system.

There are several limitations to the study. First, only NurSultan city's general public participated in the survey. It was limiting the findings to one locality. Second, RVMs in this study were studied only for plastic waste, which could be further extended for other types of waste. Third, the whole supply chain of the waste was not under the investigation, and the payback period was not estimated. Further research is required to integrate Industry 4.0 technologies with the proposed RVMs.

Acknowledgments The authors would like to thank Nazarbayev University for funding this article under the Faculty Development Competitive Research Grant Program (FCDRGP) Grant No. 110119FD4524.

Open Access This article is licensed under a Creative Commons Attribution 4.0 International License, which permits use, sharing, adaptation, distribution and reproduction in any medium or format, as long as you give appropriate credit to the original author(s) and the source, provide a link to the Creative Commons licence, and indicate if changes were made. The images or other third party material in this article are included in the article's Creative Commons licence, unless indicated otherwise in a credit line to the material. If material is not included in the article's Creative Commons licence and your intended use is not permitted by statutory regulation or exceeds the permitted use, you will need to obtain permission directly from the copyright holder. To view a copy of this licence, visit http://creativecommons.org/licenses/by/4.0/.

\section{References}

1. The Guardian (2017) A million bottles a minute: world's plastic binge as dangerous as climate change. Available at: $<$ https://www. 
theguardian.com/environment/2017/jun/28/a-million-a-minut e-worlds-plastic-bottle-binge-as-dangerous-as-climate-change>

2. World Economic Forum, Ellen MacArthur Foundation and McKinsey and Company, (2016). The new plastics economy-rethinking the future of plastics. Available at: $<\mathrm{http}: / / \mathrm{www}$.ellenmacar thurfoundation.org/publications $>$.

3. Van Cauwenberghe L, Janssen C (2014) Microplastics in bivalves cultured for human consumption. Environ Pollut 193:65-70. https ://doi.org/10.1016/j.envpol.2014.06.010

4. Straub C (2019). Indorama will invest to meet increased RPET demand. Plastics recycling. Last updated 2019-09-05. [Online] Available at: $<$ https://resource-recycling.com/plastics/2019/09/05/ indorama-will-invest-to-meet-increased-rpet-demand/> .

5. Strydom W (2018) Barriers to household waste recycling: empirical evidence from South Africa. Recycling 3(3):41

6. Winterich KP, Nenkov GY, Gonzales GE (2019) Knowing what it makes: how product transformation salience increases recycling. J Marketing. https://doi.org/10.1177/0022242919842167

7. Pramita S, Mamatha S, Parathamesh M, Abhishek G, Deeksha R, \&amp; Srikanth, U. (2019) A study on challenges for adoption of reverse vending machine: a case of North Bengaluru, India. Retrieved September 27, 2020, from http://tiikmpublishing.com/ data/conferences/doi/wcwm/26510251.2019.1202.pdf

8. nyc.gov (2017) Review of voluntary recycling incentive pilot programs for NYCHA, per Local Law 49 (2017) (16-316.4). nyc.gov/ sanitation

9. Kabugu, S.M. Feasibility study on how to introduce a depositrefund system in Nairobi, Kenya. Lahti University of Applied Sciences. 2015. pp. 26 Available: https://www.theseus.fi/bitstream/ handle/10024/102585/Kabugu_Simon.pdf?sequence=1\&isAll owed $=\mathrm{y}$

10. Veolia (2019) Reverse vending machines. Available at https:// www.veolia.co.uk/services/waste-management/commercial-waste -collection/reverse-vending-machines-rvms

11. Kjølberg T (2018) Norway's successful plastic and metal recycling system. Retrieved September 27, 2020, from https://www.daily scandinavian.com/norways-successful-plastic-metal-recyclingsystem/

12. X5 и Coca-Cola начали переработку тары - CRE. (2019, July 15). Retrieved September 27, 2020, from https://www.cre.ru/ news $/ 76948$

13. Tomra (2019) The reurn-to-retail collection model for container deposit schemes. Accessed: 13.11.2019 [Online]. Available: https ://www.tomra.com/en/collection/reverse-vending/case-studies/ return-to-retail-model

14. Ministry of foreign affairs Republic of Kazakhstan. Astana population agglomeration nears 1.2 million. Last modified: 2.07.2018 [Online]. Available: http://www.mfa.gov.kz/ms/kuala-lumpur/ content-view/astana-population-agglomeration-nears-12-million

15. Taylor-Smith K and Thomson L (2020) Recycling of high-density polyethylene (HDPE Or PEHD). [Online] Available : <https:// www.azocleantech.com/article.aspx?ArticleID=255>

16. Hessing T (2019) Quality Function Deployment (QFD) And House Of Quality (HOQ). [online] Six Sigma Study Guide. Available at: < https://sixsigmastudyguide.com/house-of-quality-hoq/ $>$ [Accessed 9 April 2020]

17. Noordzij M, Tripepi G, Dekker FW, Zoccali C, Tanck MW, Jager KJ (2010) Sample size calculations: basic principles and common pitfalls. Nephrol Dial Transplant 25(5):1388-1393. https://doi. org/10.1093/ndt/gfp732

18. Whatissixsigma.net (2020) What is House of Quality/QFD Example. Available at: < https://www.whatissixsigma.net/house-ofquality-qfd/>. [Accessed 9 April 2020].

19. Arvind (2018) Detail Explanation About The HOQ ( House Of Quality ) Concept In Engi... [online] Slideshare.net. Available at: < https://www.slideshare.net/ntarvind/detail-explanatio n-about-the-hoq-house-of-quality-concept-in-engineering-desig $\mathrm{n}>$ [Accessed 9 April 2020].

20. Master of project academy (2020) Blog. n.d. 6 Steps to build a house of quality. [online] Available at: < https://blog.masterofpr oject.com/house-of-quality/ > [Accessed 9 April 2020]

21. Businessdictionary.com (2020) Definitons. Available at: < http:// www.businessdictionary.com/definition/system.html/>. [Accessed 9 April 2020].

22. nas (2006) The first version of this article is completely based on the NAS SYSTEM ENGINEERING MANUAL SECTION 4.4 VERSION 3.1 06/06/06.

23. Reverse vending machine market—global industry analysis, size, share, growth, trends, and forecast 2017 - 2025. (n.d.). Retrieved October 04, 2020, from https://www.transparencymarketresearc h.com/reverse-vending-machine-market.html

24. UML (2020) UML Use case diagram tutorial, Available at: $<$ https ://www.lucidchart.com/pages/uml-use-case-diagram $>$ [Accessed 9 April 2020]

25. Zeid A, Al-Mutairi T, Al-Mayyan T, Al-Shatti M, Ashkanani $M$ et al (2012) Reverse poverty: an automated recycling reverse vending machine. In: Proceedings of the international conference on e-Learning, e-Business, enterprise information systems, and e-Government (EEE), The steering committee of The World Congress in Computer Science, Computer Engineering and Applied Computing (WorldComp), Athens, pp 1-7. http://worldcompproceedings.com/proc/p2012/EEE7607.pdf

26. Oliver D, Kelliher T, Keegan J (1997) Engineering complex systems with models and objects. McGraw-Hill, New York

27. Tri Nguyen M (2020) [online] Users.cecs.anu.edu.au. Available at: <https://users.cecs.anu.edu.au/ u3951377/student_work/ example_work/14_2225_irp_minh.pdf $>$ [Accessed 18 October 2020].

28. Gaur A, Mathuria D, Priyadarshini R (2018) A simple approach to design reverse vending machine. Int J Elect Elect Comput Syst 7(3):110-119

29. System engineering fundamentals (2001) Fort belvoir. Department of Defense Systems Management College, Virginia

30. Deseng.ryerson.ca. (2020) Case study: reverse vending machine [Designwiki]. [online] Available at: <https://deseng.ryerson.ca/ dokuwiki/design:reverse_vending_machine $>$ [Accessed 6 October 2020].

Publisher's Note Springer Nature remains neutral with regard to jurisdictional claims in published maps and institutional affiliations. 